\title{
Short exposure to acetylene to distinguish between nitrifier and denitrifier nitrous oxide production in soil and sediment samples
}

\author{
Ronald A. Kester $^{\mathrm{a},{ }^{*}}$, Wietse de Boer ${ }^{\mathrm{a}}$, Hendrikus J. Laanbroek ${ }^{\mathrm{b}}$ \\ ${ }^{a}$ Department of Plant-Microorganism Interactions, Centre for Terrestrial Ecology, Netherlands Institute of Ecology, P.O. Box 40 , \\ 6666 ZG Heteren, The Netherlands \\ ${ }^{\mathrm{b}}$ Department of Microbial Ecology, Centre for Limnology, Netherlands Institute of Ecology, Nieuwersluis, The Netherlands
}

Received 2 January 1996; revised 7 March 1996; accepted 8 March 1996

\begin{abstract}
The contribution of nitrifiers and denitrifiers to the nitrous oxide production in slurries of calcareous silt loam and river bank sediment at different oxygen concentrations was determined using acetylene as nitrification inhibitor. The addition of $10 \mathrm{~Pa}$ acetylene resulted in inhibition of nitrous oxide production at oxic conditions, but strongly enhanced the nitrous oxide production at oxygen-poor and anoxic conditions. Inhibition of nitrification by short exposure (1 to $24 \mathrm{~h})$ to high concentrations of acetylene (100 Pa to $10 \mathrm{kPa}$ ) was tested using the same samples. After the removal of acetylene, nitrification was inhibited almost completely ( $82 \%$ to $89 \%$ ) for at least 6 days whereas nitrous oxide reduction was restored within a day. It was concluded that the 'short exposure' inhibition method resulted in adequate nitrification inhibition without repressing the nitrous oxide reduction in anoxic nitrate-rich microsites and that the method was suitable for assessing the nitrifier contribution to the nitrous oxide emission of intact soil and sediment cores.
\end{abstract}

Keywords: Nitrous oxide emission; Nitrification; Denitrification; Soil; Sediment

\section{Introduction}

Nitrous oxide contributes to the greenhouse effect and is also involved in the ozone depletion of the stratosphere [1]. Most atmospheric nitrous oxide has been emitted from soils [2]. Denitrification and chemolithotrophic nitrification (later on referred to as nitrification) appear to be the main sources of the nitrous oxide emission [3]. Klemedtsson et al. [4] developed the so-called PPM method (parts per million method, referring to the low acetylene concen-

\footnotetext{
* Corresponding author. Tel: +31 (264) 791 306; Fax: + 31 (264) 723 227; E-mail: kester@njoo.nl

${ }^{1}$ Publication No. 2141 NIOO-CTO.
}

tration used) to investigate the contribution of nitrification and denitrification to nitrous oxide emission. A low partial pressure of acetylene (1-10 Pa) was used to inhibit nitrification and, consequently, its contribution to the nitrous oxide production. The difference between nitrous oxide production in a control without acetylene and in the acetylene treatment was ascribed to nitrification. The remaining nitrous oxide production in the acetylene treatment was assigned to denitrification. As compared to dissolved inhibitors, addition of acetylene gas has minor effects on the aeration of the soil sample and it diffuses rapidly into the soil [5]. A major drawback of the PPM method is that the nitrous oxide reduction by denitrifiers is also sensitive to acetylene. 
Although 1 to $10 \mathrm{kPa}$ acetylene is commonly used to inhibit nitrous oxide reduction in soils completely [6], substantial inhibition ( $10 \%$ to more than $50 \%$ ) can already be reached with 1 to $10 \mathrm{~Pa}$ acetylene [7]. Partial inhibition of nitrous oxide reduction can result in the underestimation of nitrifier nitrous oxide production by the PPM method. This problem is probably more serious in soils with high denitrification activity such as those with abundant anoxic micro-sites. Klemedtsson and Hansson [5] reviewed the PPM method and concluded that the drawbacks of the PPM method may be negligible in some soils, but might be more apparent in other soils.

Several authors [8-10] reported the slow recovery of nitrification in soil samples after being exposed to acetylene. Exposure of a Nitrosomonas europaea culture to $10 \mathrm{kPa}$ acetylene for $20 \mathrm{~h}$ resulted in $200 \mathrm{~h}$ inhibition of ammonium oxidation and a decrease in the number of viable cells of approximately 2 orders of magnitude [9]. Acetylene is a suicide substrate for the ammonia mono-oxygenase, the first enzyme in the ammonium oxidation pathway, and the inhibition is irreversible [11]. Hynes and Knowles [9] and Hyman and Arp [12] suggested that de novo synthesis of ammonia mono-oxygenase is necessary after exposure to acetylene. Hyman and Arp [12] demonstrated that more than $95 \%$ of the nitrite-generating activity of Nitrosomonas europaea was lost within $15 \mathrm{~min}$ when exposed to acetylene.

Nitrous oxide reductase of Paracoccus denitrificans is non-competitively inhibited by acetylene [13], and acetylene does not prevent the synthesis of nitrous oxide reductase [14] c.f. [15]. Balderston et al. [16] showed that the inhibition of nitrous oxide reductase in Pseudomonas perfectomarinus was immediately alleviated after removal of $2 \mathrm{kPa}$, but not 3 $\mathrm{kPa}$ acetylene.

In general, inhibition of ammonia monooxygenase interferes directly with the energy generating system of ammonia-oxidizing bacteria, while inhibition of nitrous oxide reduction in denitrifying bacteria results only in a lower efficiency of nitrate as an electron acceptor. Hence, recovery of nitrification would be expected to take much longer than recovery of nitrous oxide reduction after exposure to acetylene.

Davidson [17] used this principle to specifically inhibit nitrifier nitrous oxide production. Sieved soil was exposed to $10 \mathrm{kPa}$ acetylene for $24 \mathrm{~h}$, vented $1 \mathrm{~h}$ and subsequently subjected to a $24 \mathrm{~h}$ wetting experiment. Below field capacity, the acetylene treatment inhibited the nitrous oxide production, above field capacity there was a stimulation of nitrous oxide production by the acetylene treatment, although not significant.

As stated above, anoxic (micro)sites in soils and sediments are potentially interfering with the PPM method. In this study we tested the PPM method at different oxygen concentrations to mimic oxic, oxygen-poor and anoxic microsites. Furthermore we developed inhibition protocols based on the above described principle of slow nitrifier recovery, to avoid the unwanted inhibition of nitrous oxide reductase in anoxic microsites. In all experiments slurries of soil or sediment samples were used to avoid local depletion of oxygen, nitrate and ammonium.

\section{Materials and methods}

\subsection{Soil and sediment samples}

Soil or sediment samples were collected in the spring of 1991 unless indicated otherwise. At the experimental farm Lovinkhoeve in the Noordoostpolder, The Netherlands, samples were taken from two fields on calcareous silt loam, one with a conventional arable farming system (indicated as Lc) and one with an integrated arable farming system (indicated as $\mathrm{Li}$ ). Soil characteristics and farming systems have been described elsewhere $[18,19]$. Along the Schelde river (Belgium), samples were taken at Notelaar (indicated as N) in a reed vegetation and at Burcht (indicated as B) in a bullrush vegetation. Both sites are within the tidal freshwater zone of the river, described elsewhere [20]. 50 cores per site $(2.5 \mathrm{~cm}$ diameter) were taken from the upper $5 \mathrm{~cm}$ of the soil or sediment. Pooled field-moist samples were sieved ( $4 \mathrm{~mm}$ mesh) and stored at $4^{\circ} \mathrm{C}$ until further use. Some characteristics of the soils and sediments are given in Table 1.

\subsection{The effect of the PPM method at different oxy- gen concentrations}

Slurries $(1: 10 \mathrm{w} / \mathrm{v})$ were made from field-moist, sieved soil or sediment ( $10 \mathrm{~g}$ dry weight) and a 
Table 1

Selected properties of the upper $5 \mathrm{~cm}$ of the sampled soils and sediments

\begin{tabular}{|c|c|c|c|c|c|c|c|}
\hline \multirow[t]{2}{*}{ Site } & \multirow[t]{2}{*}{ Date } & \multirow[t]{2}{*}{ Moisture (w/w) } & \multirow[t]{2}{*}{ Organic matter $(w / w)$} & \multirow[t]{2}{*}{$\mathrm{pH}-\mathrm{H}_{2} \mathrm{O}$} & \multicolumn{3}{|c|}{$\mathrm{mg} \mathrm{N} \mathrm{kg}^{-1}$} \\
\hline & & & & & $\mathrm{NH}_{4}^{+}$ & $\mathrm{NO}_{2}^{-}$ & $\mathrm{NO}_{3}^{-}$ \\
\hline $\mathrm{Li}$ & $12-3-1991$ & 0.28 & 0.055 & 8.0 & 0.22 & 0.52 & 6.64 \\
\hline $\mathrm{Li}$ & $8-5-1992$ & 0.21 & 0.045 & 8.0 & 0.17 & n.d. & 68.5 \\
\hline Lc & $12-3-1991$ & 0.27 & 0.048 & 8.0 & 0.49 & 0.08 & 5.32 \\
\hline B & $15-4-1991$ & 0.85 & 0.088 & 7.3 & 2.37 & 0.00 & 3.01 \\
\hline B & 28-4-1992 & 1.16 & 0.109 & 7.2 & 11.02 & 0.40 & 9.17 \\
\hline $\mathbf{N}$ & $15-4-1991$ & 0.94 & 0.081 & 7.4 & 5.25 & 0.00 & 8.26 \\
\hline
\end{tabular}

Abbreviations used: Li, Lovinkhoeve integrated farming system; Lc, Lovinkhoeve conventional farming system; B, Burcht; N, Notelaar; n.d., not determined. Moisture content, organic matter content and mineral $\mathrm{N}$-content are expressed on dry-weight basis.

solution of $0.2 \mathrm{mM} \mathrm{KH} \mathrm{PO}_{4}, 0.2 \mathrm{mM} \mathrm{CaCl}_{2}$ and $0.2 \mathrm{mM} \mathrm{MgSO}_{4}$ in $300 \mathrm{ml}$ glass bottles. The bottles were sealed with a butyl rubber septum. Prior to testing, slurries were incubated for 5 days in the dark at $20^{\circ} \mathrm{C}$ on a rotary shaker $(100 \mathrm{rpm})$ under anoxic, oxygen-poor ( $1 \%$ oxygen at the start of the preincubation) and oxic conditions.

Testing of the effect of $10 \mathrm{~Pa}$ acetylene was started with the addition of $5 \mathrm{mM} \mathrm{NH} \mathrm{NO}_{3}$. The oxygen status in the bottles at the start of the preincubation was restored. Acetylene (acetone-free, Hoekloos, Schiedam, The Netherlands) was injected in half of the bottles, to obtain $10 \mathrm{~Pa}$ partial pressure in the headspace. The bottles were further incubated in the dark as before. Nitrous oxide, acetylene and oxygen concentrations in the headspace and $\mathrm{NH}_{4}^{+}$, $\mathrm{NO}_{2}^{-}$and $\mathrm{NO}_{3}^{-}$concentrations in the slurry were measured regularly during the incubation period. The incubations with Notelaar and Burcht slurries were terminated after 4 and 5 days, the oxic incubations of Lovinkhoeve slurries after 6 days, the anoxic and oxygen-poor incubations of Lovinkhoeve slurries after 3 days.

\subsection{Short exposure of Burcht and Lovinkhoeve slur- ries to acetylene}

Oxic and anoxic slurries from Lovinkhoeve soil (integrated farming system) and Burcht sediment were prepared as described above and preincubated for 3 to 5 days. Slurries of Burcht sediment were exposed to 0,100 $\mathrm{Pa}$ and $10 \mathrm{kPa}$ acetylene for $24 \mathrm{~h}$ and successively sparged with air (oxic preincubation) or nitrogen (anoxic preincubation). Slurries of
Lovinkhoeve soil were treated likewise with exposure to 0 and $100 \mathrm{~Pa}$ acetylene. The effect of acetylene on nitrification was examined by monitoring the nitrate and nitrite production after exposure to acetylene in oxic slurries amended with $5 \mathrm{mM}$ ammonium. The difference between the amount of nitrite + nitrate accumulated after 6 days in the acetylene treated slurries and the controls was used to calculate the percentage of inhibition. The effect of acetylene on nitrous oxide reduction by denitrifiers was tested by monitoring the consumption of added nitrous oxide in anoxic slurries amended with $5 \mathrm{mM}$ nitrate. The amount of nitrous oxide added was dependent on the soil or sediment used in the test.

\subsection{Short exposure of Lovinkhoeve soil and Burcht sediment at field-moist conditions to acetylene.}

In order to shorten the exposure time and to avoid excessive sparging with nitrogen or air to discard the acetylene, field-moist soil or sediment samples were exposed to acetylene prior to slurry-incubation. Sieved field-moist samples of Lovinkhoeve soil and Burcht sediment (collected in the spring of 1992) were placed in 1.51 gastight jars and exposed to 0 , $100 \mathrm{~Pa}$ (Burcht only) or $10 \mathrm{kPa}$ acetylene for $1 \mathrm{~h}$. Subsequently, the exposed samples were placed on a dish for $1 \mathrm{~h}$ to facilitate the evaporation of acetylene. Slurries were made as described above and tests for inhibition of nitrification and nitrous oxide reduction were initiated immediately. Nitrification inhibition and nitrous oxide reduction were tested as described above, except for Burcht samples, in which the inhibition of nitrous oxide reduction was tested by 
monitoring the nitrous oxide concentration in the headspace without addition of nitrous oxide. The inhibition of nitrification in Burcht samples was tested during 3 in stead of 6 days.

\subsection{The effect of chloramphenicol on nitrous oxide reduction after exposure to acetylene}

Field-moist Lovinkhoeve soil was exposed to 0 or $10 \mathrm{kPa}$ acetylene for $1 \mathrm{~h}$ as described above. Reduction of added nitrous oxide was tested in slurries which contained $0.1 \mathrm{~g}$ chloramphenicol per litre. The effectiveness of this chloramphenicol dose in inhibiting the de novo synthesis of proteins was tested previously (unpublished results).

\subsection{Analytical procedures}

The $\mathrm{pH}$ of the soil and sediment samples was measured in a $1: 5(\mathrm{w} / \mathrm{v})$ soil/sediment-water slurry after $2 \mathrm{~h}$ shaking. Concentrations of ammonium, nitrite and nitrate in $2 \mathrm{M} \mathrm{KCl}$ extracts of the soil and sediment samples and the incubated slurries were determined with a Technion Traacs 800 autoanalyzer. Organic matter content of the samples was determined by loss-on-ignition $\left(4 \mathrm{~h} 550^{\circ} \mathrm{C}\right)$. Nitrous oxide, acetylene and oxygen in the headspace were measured with a gas-chromatograph (Carlo Erba GC
6000 ) equipped with an ECD (nitrous oxide below 100 ppmv) and a HWD (nitrous oxide above 100 ppmv, oxygen and acetylene). Gases were separated on a Hayesep Q column (nitrous oxide and acetylene) and a Molsieve $5 \AA$ column (oxygen), both operated at $50^{\circ} \mathrm{C}$ with helium as carrier gas.

\section{Results}

\subsection{The effect of the PPM method at different oxy- gen concentrations}

Under oxic conditions, $10 \mathrm{~Pa}$ acetylene almost completely inhibited the nitrous oxide emission from the soil and sediment slurries (Fig. 1A), which indicates that nitrifiers were the most important nitrous oxide producers in these oxic slurries. Controls under oxygen-poor conditions (Fig. 1B) showed greatly reduced nitrous oxide emission compared with oxic controls. In contrast to oxic conditions, $10 \mathrm{~Pa}$ acetylene strongly enhanced the emission of nitrous oxide in oxygen-poor $\mathrm{Li}, \mathrm{B}$ and $\mathrm{N}$ slurries. In oxygen-poor $\mathrm{Li}, \mathrm{B}$ and $\mathrm{N}$ slurries nitrous oxide emission of the 10 $\mathrm{Pa}$ acetylene treatment exceeded the oxygen-poor controls 36, 147 and 793 times, respectively. Even though no oxygen was added to $\mathrm{Lc}$ and $\mathrm{Li}$ incubations, oxygen concentrations remained between

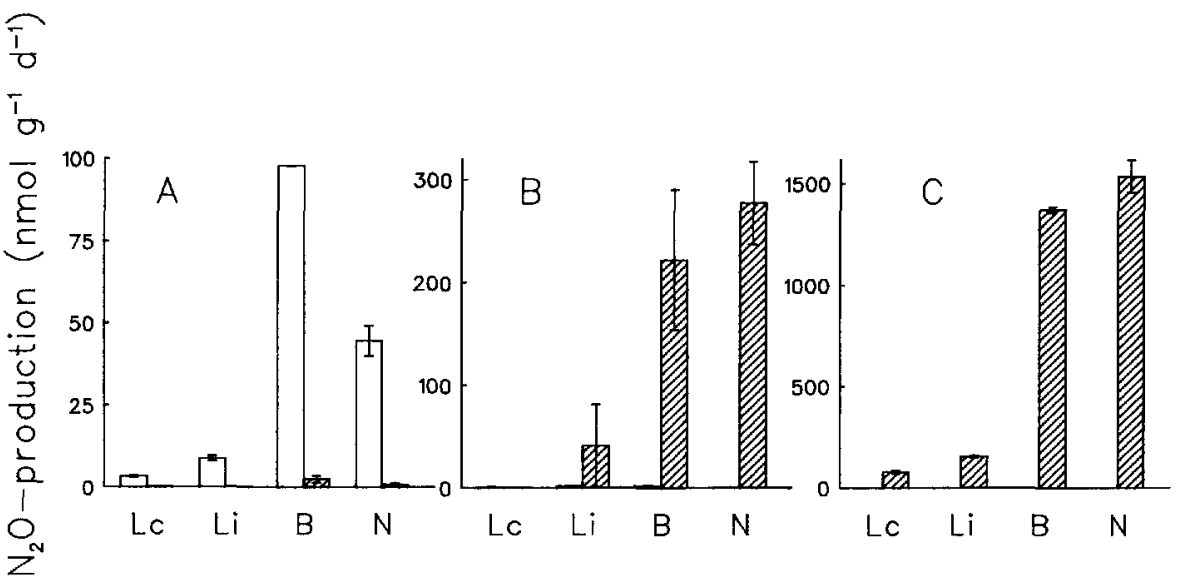

Fig. 1. Nitrous oxide production in oxic (A), oxygen-poor (B) and anoxic (C) soil or sediment slurries with 10 Pa acetylene (shaded bars) and without acetylene (open bars). Slurries $(1: 10 \mathrm{w} / \mathrm{v})$ were made of soil or sediment samples from Lovinkhoeve conventional farming system (Lc), Lovinkhoeve integrated farming system $(\mathrm{Li})$, Burcht $(\mathrm{B})$ and Notelaar $(\mathrm{N})$. The error bars represent the standard error of the mean $(n=2)$. 
$0.39 \%$ and $2.64 \%$ in the headspace. This was not the case in the oxygen-poor incubations of $\mathrm{B}$ and $\mathrm{N}$, where, even with the regular addition of extra oxygen, some periods of anoxia were encountered (data not shown). Although anoxic conditions almost completely stopped nitrous oxide emission in the control slurries (Fig. 1C), $10 \mathrm{~Pa}$ acetylene treatment resulted in the largest nitrous oxide emission of the entire experiment for each soil or sediment slurry.

Slurries of B and N showed acetylene consumption, which was strongest in the oxic slurries. At the end of the incubation period there was no acetylene left in any of the B slurries and in the oxic $\mathrm{N}$ slurries (data not shown). In each of the slurries, there was always at least $2 \mathrm{mM}$ nitrate and $0.11 \mathrm{mM}$ ammonium present at the end of the incubations (data not shown).

\subsection{Short exposure of Burcht and Lovinkhoeve slur- ries to acetylene}

The production of nitrate and nitrite in oxic Burcht slurries was strongly inhibited by the $24 \mathrm{~h}$ exposure to acetylene (Fig. 2A). After 6 days of post-treatment incubation the $100 \mathrm{~Pa}$ and $10 \mathrm{kPa}$ acetylene exposures resulted in $89 \%$ and $94 \%$ inhibition of nitrification, respectively. Addition of nitrous oxide to the anoxic control slurries of Burcht (Fig. 3A) resulted in nitrous oxide reduction. Nitrous oxide reduction was initially inhibited after $24 \mathrm{~h}$ exposure to $100 \mathrm{~Pa}$ acetylene, but restored within a day. $24 \mathrm{~h}$ exposure to $10 \mathrm{kPa}$ acetylene inhibited nitrous oxide reduction for more than $48 \mathrm{~h}$ in Burcht slurries (data not shown). Excessive sparging with nitrogen was required to discard the acetylene from the anoxic slurries.

In oxic Lovinkhoeve slurries, nitrification was also susceptible to the $24 \mathrm{~h}$ exposure to $100 \mathrm{~Pa}$ acetylene (Fig. 2B). During the 6 days after exposure nitrate and nitrite production was inhibited for $87 \%$. Nitrous oxide reduction started almost immediately after the exposure in Lovinkhoeve slurries (Fig. 3B).

\subsection{Short exposure of Lovinkhoeve soil and Burcht sediment at field-moist conditions to acetylene}

In order to shorten the exposure time and to avoid excessive sparging with nitrogen or air to discard the

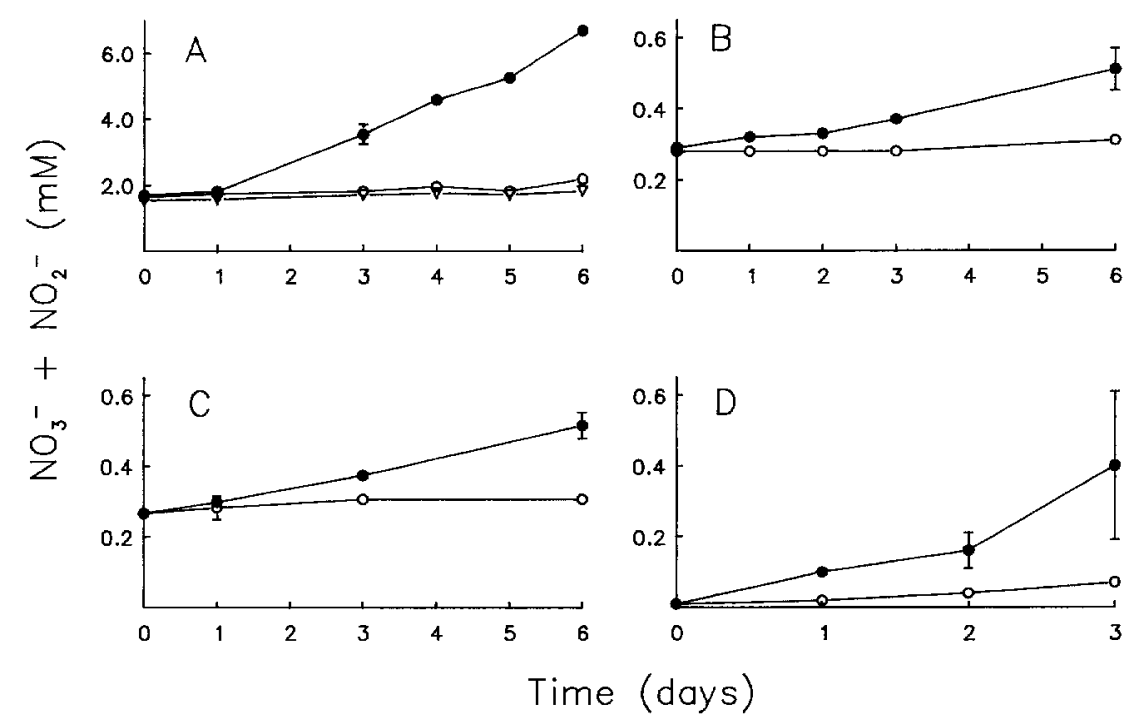

Fig. 2. Nitrate plus nitrite concentration in oxic slurries of A: Burcht sediment after $24 \mathrm{~h}$ exposure to $0 \mathrm{~Pa}$ (closed circles), $100 \mathrm{~Pa}$ (open circles) or $10 \mathrm{kPa}$ acetylene (triangles) and subsequent sparging with air; $\mathbf{B}$ : Lovinkhoeve soil after $24 \mathrm{~h}$ exposure to $0 \mathrm{~Pa}$ (closed circles) and $100 \mathrm{~Pa}$ acetylene (open circles) and subsequent sparging with air; $\mathbf{C}$ : Lovinkhoeve soil after $1 \mathrm{~h}$ exposure to $0 \mathrm{~Pa}$ (closed circles) and 10 $\mathrm{kPa}$ acetylene (open circles) in field-moist state and subsequent evaporation of the acetylene; $\mathbf{D}$ : Burcht sediment after $1 \mathrm{~h}$ exposure to $0 \mathrm{~Pa}$ (closed circles) and $10 \mathrm{kPa}$ acetylene (open circles) in field-moist state and subsequent evaporation of the acetylene. The error bars represent the standard error of the mean ( $A$ and $C n=3 ; B$ and $D n=4$ ). 


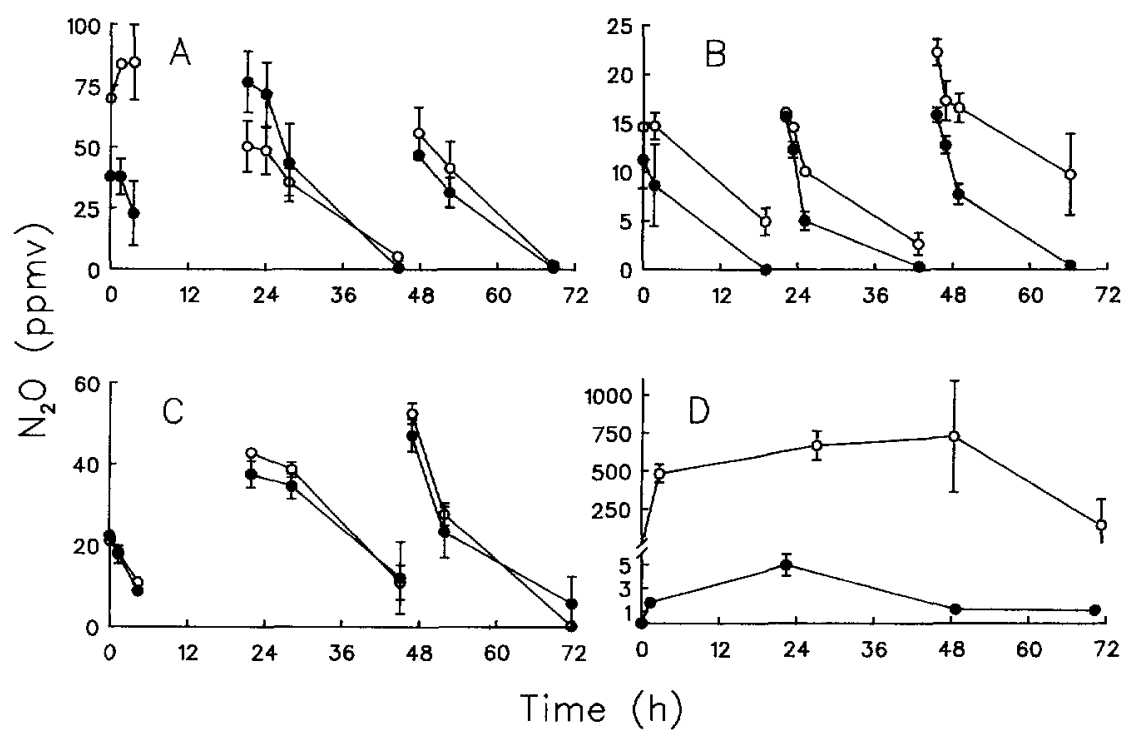

Fig. 3. The nitrous oxide concentration in the headspace of anoxic slurries of $\mathbf{A}$ : Burcht sediment after $24 \mathrm{~h}$ exposure to $0 \mathrm{~Pa}$ and $100 \mathrm{~Pa}$ acetylene; B: Lovinkhoeve soil after $24 \mathrm{~h}$ exposure to $0 \mathrm{~Pa}$ and $100 \mathrm{~Pa}$ acetylene; $\mathbf{C}$ : Lovinkhoeve soil after $1 \mathrm{~h}$ exposure to $0 \mathrm{~Pa}$ and $10 \mathrm{kPa}$ acetylene in field-moist state and subsequent evaporation of the acetylene; $\mathbf{D}$ : Burcht sediment after $1 \mathrm{~h}$ exposure to $0 \mathrm{~Pa}$ and $10 \mathrm{kPa}$ acetylene in field-moist state and subsequent evaporation of the acetylene. The acetylene treatment is indicated with the open symbols, the control with closed symbols. After sparging the slurries with nitrogen, nitrous oxide was added at the beginning of the incubations and again after $22 \mathrm{~h}$ and $48 \mathrm{~h}$ (A, B and C). No nitrous oxide was added to $\mathbf{D}$. The error bars represent the standard error of the mean (A and $\mathbf{B} n=3$; $\mathbf{C}$ and $\mathbf{D} n=4)$.

acetylene, field-moist soil or sediment samples were exposed to acetylene prior to slurry-incubation. Exposure of the Lovinkhoeve soil resulted in $84 \%$ inhibition of nitrification during 6 days post treatment incubation compared to the control (Fig. 2C). In anoxic slurries, there was no effect of the exposure on the nitrous oxide reduction (Fig. 3C). Acetylene was not detectable in the Lovinkhoeve slurries.

Oxic slurries of exposed Burcht sediment ( 1 h 10 $\mathrm{kPa}$ acetylene) showed $82 \%$ inhibition of nitrification after 3 days (Fig. 2D). Anoxic slurries of control sediment initially emitted nitrous oxide, but within $24 \mathrm{~h}$ there was a net nitrous oxide reduction (Fig. 3D). Anoxic slurries of exposed Burcht sediment emitted large amounts of nitrous oxide during the first hours of incubation. Reduction of nitrous oxide started between 24 and $48 \mathrm{~h}$. Some acetylene was still present $3 \mathrm{~h}$ after the onset of the incubation, but was absent $21 \mathrm{~h}$ later (data not shown).

Exposure of Burcht sediment to $100 \mathrm{~Pa}$ acetylene for $1 \mathrm{~h}$ resulted in poor inhibition of nitrification in oxic suspensions. Emission and reduction rate of nitrous oxide in anoxic slurries of control and exposed sediment were comparable (data not shown).

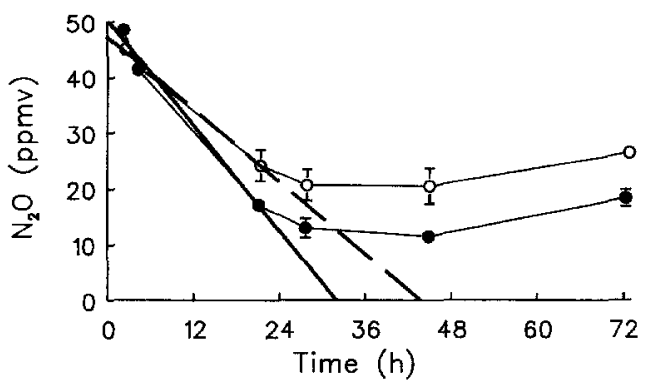

Fig. 4. The nitrous oxide concentration in the headspace of anoxic slurries of Lovinkhoeve soil with chloramphenicol after $1 \mathrm{~h}$ exposure to $0 \mathrm{~Pa}$ (closed symbols) and $10 \mathrm{kPa}$ acetylene (open symbols) in field-moist state and subsequent evaporation of the acetylene. Chloramphenicol $\left(0.1 \mathrm{~g} \mathrm{l}^{-1}\right)$ and nitrous oxide were added at the beginning of the incubations. The dashed and continuous line represent the nitrous oxide consumption rate during the first day for the acetylene treatment and control, respectively. The error bars represent the standard error of the mean $(n=3)$. 


\subsection{The effect of chloramphenicol on nitrous oxide reduction after exposure to acetylene}

Anoxic slurries of exposed Lovinkhoeve sediment (1 h $10 \mathrm{kPa}$ acetylene) and control sediment, both amended with chloramphenicol, started to reduce added nitrous oxide immediately (Fig. 4). After $24 \mathrm{~h}$ nitrous oxide concentration in the headspace stabilized and started to rise $24 \mathrm{~h}$ later, both in control and acetylene exposed slurries. The initial decrease of nitrous oxide (until $22 \mathrm{~h}$ ) was used to estimate the net nitrous oxide reduction rate. The slurries of the control soil reduced 1.57 ppmv nitrous oxide per $h$ $\left(\mathrm{R}^{2}=0.98 ; 95 \%\right.$ confidence interval $\left.1.37-1.78\right)$, and the slurries of the acetylene exposed soil reduced 1.08 ppmv nitrous oxide per $\mathrm{h}\left(\mathrm{R}^{2}=0.96 ; 95 \%\right.$ confidence interval $0.89-1.28$ ).

\section{Discussion}

\subsection{The effect of the PPM method at different oxy- gen concentrations}

The PPM method with $10 \mathrm{~Pa}$ acetylene had a stimulating effect on nitrous oxide production in oxygen-poor and anoxic slurries. It is assumed that this enhancement is the result of inhibition of nitrous oxide reduction by denitrifying bacteria, as nitrous oxide reduction by these bacteria can be partially inhibited by $10 \mathrm{~Pa}$ acetylene [7]. Anoxic and oxygen-poor microsites are common in soil [21] and $10 \mathrm{~Pa}$ acetylene will be able to enhance the nitrous oxide production by denitrifiers in these microsites leading to an underestimation of the nitrifier contribution to the nitrous oxide production. Klemedtsson et al. [4] did encounter similar problems with acetylene concentrations above $2.5 \mathrm{~Pa}$, as nitrous oxide production in soil increased at $100 \%$ water-holding capacity. Davidson et al. [22] tested the reduction of added nitrous oxide at different acetylene partial pressures in a nitrate depleted forest soil sample. Inhibition of nitrous oxide reduction was complete at $10 \mathrm{kPa}$ acetylene and almost absent at $10 \mathrm{~Pa}$. However, this experiment was designed to provide a rigorous test for complete inhibition of nitrous oxide reduction with the $10 \mathrm{kPa}$ treatment, not for testing the undesired inhibition at $10 \mathrm{~Pa}$ acetylene since very low concentrations of nitrate are known to alleviate the blockage of nitrous oxide reduction by acetylene [23-25]. Hence, partial inhibition of nitrous oxide reduction by $10 \mathrm{~Pa}$ acetylene could be expected in nitrate rich soils, but not in nitrate limited soils.

In our experiment, we used $10 \mathrm{~Pa}$ acetylene as it inhibits nitrification completely [10]. Although inhibition of nitrification is possible at lower acetylene concentrations in certain soils, consumption of acetylene by the soil microbiota may soon result in an incomplete inhibition. Acetylene consumption is reported previously by Terry and Duxbury [15] under oxic but not under anoxic conditions, whereas Culbertson et al. [26] found acetylene oxidation in anoxically incubated estuarine sediments. In the top mineral layer of an acid forest soil, consumption of acetylene $(10 \mathrm{~Pa})$ resulted in only partial inhibition of nitrification [27]. In this study, we observed acetylene consumption in samples of Schelde river sediment at all oxygen levels.

\subsection{Short exposure to acetylene}

As the PPM method with $10 \mathrm{~Pa}$ acetylene resulted in the enhancement of nitrous oxide production in oxygen-poor and anoxic slurries, we tried different protocols to specifically inhibit nitrification. Short exposure, $24 \mathrm{~h}$ to $100 \mathrm{~Pa}$ or $10 \mathrm{kPa}$ acetylene, resulted in at least $87 \%$ inhibition of nitrification during six successive days. In contrast, nitrous oxide reduction was restored within $24 \mathrm{~h}$ after exposure to $100 \mathrm{~Pa}$ acetylene. Removal of acetylene from the slurries after the $10 \mathrm{kPa}$ treatment was difficult. This was probably the cause of the delayed recovery of nitrous oxide reduction in this treatment.

The exposure of Burcht and Lovinkhoeve fieldmoist samples to $10 \mathrm{kPa}$ acetylene for $1 \mathrm{~h}$ resulted in at least $82 \%$ inhibition of nitrification, whereas $1 \mathrm{~h}$ exposure of Burcht sample to $100 \mathrm{~Pa}$ acetylene did not inhibit nitrification efficiently. Nitrous oxide reduction was not affected at all by the $10 \mathrm{kPa}$ treatment in Lovinkhoeve soil, but was strongly inhibited in Burcht sediment. Acetylene was still present at the start of the incubation of the Burcht samples and was completely consumed within $24 \mathrm{~h}$. Only after the disappearance of all the acetylene, the nitrous oxide reduction in Burcht slurries started again. Unfortunately, the differences in experimental set up of this 
particular test do not allow for direct comparison of nitrous oxide reduction activity between control and acetylene treatment. Acetylene is very soluble in water [28] and the higher water content of the fieldmoist Burcht sample, compared to the Lovinkhoeve sample, was probably the cause of the inefficient removal of the gas.

As described earlier, Davidson [17] tried a similar approach with soil samples at different moisture contents. Below field capacity, the acetylene treatment, consisting of $24 \mathrm{~h}$ exposure to $10 \mathrm{kPa}$ acetylene prior to incubation, inhibited the nitrous oxide production. Above field capacity there was a stimulation of nitrous oxide production, although not significant, by the acetylene treatment. In another experiment, soil cores from a seasonally dry tropical forest were exposed to $10 \mathrm{kPa}$ acetylene for $18 \mathrm{~h}$ and subsequently after $2 \mathrm{~h}$ venting, to $10 \mathrm{~Pa}$ [29]. Dry cores which received an artificial $4 \mathrm{~cm}$ rainfall, showed a doubling of nitrous oxide production in the acetylene treatment after $3 \mathrm{~h}$ post-treatment incubation. The authors suggested that the $18 \mathrm{~h} 10 \mathrm{kPa}$ acetylene exposure caused an inhibition of the nitrous oxide reduction, but the permanent exposure to $10 \mathrm{~Pa}$ acetylene could have been responsible as well.

\subsection{De novo synthesis of nitrous oxide reductase}

The addition of chloramphenicol showed that, without de novo synthesis, nitrous oxide reduction activity of Lovinkhoeve slurries had decreased by $31 \%$ after $1 \mathrm{~h}$ exposure to $10 \mathrm{kPa}$ acetylene, compared with the control. Both in the control and the acetylene treatment, the inhibition of de novo synthesis eventually resulted in a net nitrous oxide production. This is probably the result of a relative decrease of nitrous oxide reductase activity compared to the activity of the preceding denitrification reductases. A relatively high turnover rate of nitrous oxide reductase could be one of the reasons for this phenomenon. Similar slurries without chloramphenicol (results not shown) maintained nitrous oxide reduction activity. Hence, even in the control without acetylene, de novo synthesis of nitrous oxide reductase within $24 \mathrm{~h}$ is necessary to maintain nitrous oxide reduction activity. Since acetylene does not prevent the synthesis of nitrous oxide reductase [14] c.f. [15], partial inhibition of nitrous oxide reductase after exposure is alleviated very quickly by de novo synthesis of this enzyme.

\subsection{Applications of the 'short exposure' inhibition}

Short exposure to $10 \mathrm{kPa}$ acetylene appears to be promising for nitrification inhibition in undisturbed soil or sediment cores. Most nitrification inhibitors have to be added as an aqueous or organic solution which disturbs the aeration in the core far more than the addition of a gas does. Methyl fluoride is another nitrification-inhibiting gas, which has only recently been applied but shows promising features as well [30].

Within a soil or sediment core, diffusion of acetylene to nitrifying and denitrifying bacteria will take some time. Hynes and Knowles [9] stated that the recovery of acetylene exposed $N$. europaea cultures occurred more rapidly with higher cell densities and shorter exposure time. The ammonia monooxygenase must be catalytically competent for acetylene-induced inactivation to occur [11]. Hence, cells must be active during the exposure period. Longer exposure time and lower cell densities decrease the number of viable cells not inhibited at the end of the exposure period. It is feasible that a major part of the recovery results from the growth of the non-inhibited fraction of the population. Fortunately, active nitrifiers are located at sites in soil which are readily accessible to diffusing gas [31], whereas active denitrifiers are usually located in places which are difficult to reach by oxygen or other gases. Hence, during short exposure of a soil core, the acetylene may reach the active nitrifying community, while slow diffusion may prevent contact with the active denitrifying community.

In cores of wet soils or sediments, slow evaporation of acetylene after the exposure is expected. The danger exists that the soil or sediment becomes nitrate depleted before all acetylene is gone and nitrous oxide production can be measured. The depletion of nitrate results in an underestimation of nitrous oxide production by denitrification. The depletion of nitrate should be monitored in these kind of samples. In sediments, however, the active nitrifying and denitrifying layers are often found very close to the surface [32]. The use of short cores, containing only the layers of interest, will diminish amount of 
acetylene dissolving in the sediment during exposure, which facilitates the efficient evaporation of the gas after exposure.

We performed the tests for nitrous oxide production and reduction with a high nitrate background to ensure that the potential inhibition of nitrous oxide reductase was not alleviated by limiting nitrate supply. Under these circumstances, the PPM method resulted in strong enhancement of nitrous oxide production in oxygen-poor and anoxic incubations. In contrast, nitrous oxide reduction started rapidly after short exposure to acetylene as soon as the acetylene had completely disappeared. The 'short exposure' inhibition method results in sufficient nitrification inhibition without repressing the nitrous oxide reduction in anoxic nitrate containing microsites. This method seems suitable for assessing the contribution of nitrification to the nitrous oxide emission of intact soil and sediment cores. However, like every nitrification inhibition technique, the 'short exposure' method does not identify the source of the remaining nitrous oxide production after inhibition. In general, denitrification will be the remaining source [3], but heterotrophic nitrification, non-denitrifying nitrate reduction or fungal activity might be important in specific soils. The removal of acetylene is the bottle neck in the 'short exposure' method and soil moisture content seems to influence the rate of its disappearance.

\section{Acknowledgements}

We thank Coen Vrijland for his assistance in the nitrous oxide measurements, and Jan Woldendorp and George Kowalchuk for critical reading of the manuscript.

\section{References}

[1] Crutzen, P.J. (1981) Atmospheric chemical processes of the oxides of nitrogen, including nitrous oxide. In: Denitrification, Nitrification and Atmospheric Nitrous Oxide (Delwiche, C.C., Ed.), pp. 17-44. Wiley and Sons Inc., New York.

[2] Duxbury, J.M. (1994) The significance of agricultural sources of greenhouse gases. Fert. Res. 38, 151-163.

[3] Firestone, M.K. and Davidson, E.A. (1989) Microbiological basis of $\mathrm{NO}$ and $\mathrm{N}_{2} \mathrm{O}$ production and consumption in soil. In:
Exchange of Trace Gases between Terrestrial Ecosystems and the Atmosphere (Andrea, M.O. and Schimel D.S., Eds.), pp. 7-21. Dahlem Workshop Reports, John Wiley and Sons, Chichester.

[4] Klemedtsson, L. Svensson, B.H. and Rosswall, T. (1988) A method of selective inhibition to distinguish between nitrification and denitrification as sources of nitrous oxide in soil. Biol. Fertil. Soils 6, 122-119.

[5] Klemedtsson, L. and Hansson, G. (1990) The use of acetylene for a quantification of $\mathrm{N}_{2}$ and $\mathrm{N}_{2} \mathrm{O}$ production from biological processes in soil. In: Denitrification in Soil and Sediment (Revsbech, N.P. and Sørensen, J., Eds.), pp. 167180. Plenum Press, New York.

[6] Tiedje, J.M., Simkins, S. and Groffman, P.M. (1989) Perspectives on measurement of denitrification in the field including recommended protocols for acetylene based methods. In: Ecology of Arable Land-Perspectives and Challenges (Clarholm, M. and Bergstrom, L., Eds.), pp. 217-240. Kluwer Academic Publishers, Dordrecht.

[7] Knowles, R. (1986) Aspects of nitrification and denitrification. In: Proceedings of the Fourth International Symposium on Microbial Ecology (Megusar, F. and Gantar, M., Eds.), pp. 319-324. Slovene Society for Microbiology, Ljublana.

[8] Walter, H.M., Keeney, D.R. and Fillery, I.R. (1979) Inhibition of nitrification by acetylene. Soil Sci. Soc. Am. J. 43, 195-196.

[9] Hynes, R.K. and Knowles, R. (1982) Effect of acetylene on autotrophic and heterotrophic nitrification. Can. J. Microbiol. 28, 334-340.

[10] Berg, P., Klemedtsson, L. and Roswall, T. (1982) Inhibitory effects of low partial pressure of acetylene on nitrification. Soil Biol. Biochem. 14, 301-303.

[11] Hyman, M.R. and Wood, P.M. (1985) Suicidal inactivation and labelling of ammonia mono-oxygenase by acetylene. Biochem. J. 227, 719-725.

[12] Hyman, M.R. and Arp, D.J. (1992) ${ }^{14} \mathrm{C}_{2} \mathrm{H}_{2}$-labelling and ${ }^{14} \mathrm{CO}_{2}$-labelling studies of the de-novo synthesis of polypeptides by Nitrosomonas europaea during recovery from acetylene and light inactivation of ammonia monooxygenase. J. Biol. Chem. 267, 1534-1545.

[13] Kristjansson, J.K. and Hollocher, T.C. (1980) First practical assay for soluble nitrous oxide reductase of denitrifying bacteria and a partial kinetic characterization. J. Biol. Chem. 255, 704-707.

[14] Erich, M.S. (1980) Measurement of denitrification using the acetylene blocking technique. M.S. thesis, Cornell Univ. Ithaca, New York.

[15] Terry, R.E. and Duxbury, J.M. (1985) Acetylene decomposition in soils. Soil Sci. Soc. Am. J. 49, 90-94.

[16] Balderston, W.L., Sherr, B. and Payne, W.J. (1976) Blockage by acetylene of nitrous oxide reduction in Pseudomonas perfectomarinus. Appl. Environ. Microbiol. 31, 504-508.

[17] Davidson, E.A. (1992) Sources of nitric oxide and nitrous oxide following wetting of dry soil. Soil Sci. Soc. Am. J. 56, 95-102.

[18] Kooistra, M.J., Lebbink, G. and Brussaard, L. (1989) The Dutch programme on soil ecology of arable farming systems: 
2. Geogenesis, agricultural history, field site characteristics and present farming systems at the Lovinkhoeve experimental farm. Agric. Ecosyst. Environ. 27, 361-387.

[19] Van Faassen, H.G. and Lebbink, G. (1990) Nitrogen cycling in high-input versus reduced-input arable farming. Neth. J. Agri. Sci. 38, 265-282.

[20] Middelburg, J.J., Klaver, G., Nieuwenhuize, J., Markusse, R.M., Vlug, T., Jaco, F. and van der Nat, W.A. (1995) Nitrous oxide emissions from estuarine intertidal sediments. Hydrobiologia 311, 43-55.

[21] Leffelaar, P.A. (1987) Dynamics of partial anaerobiosis, denitrification, and water in soil: experiments and simulation. Ph.D. thesis, pp. 117. Wageningen Agricultural University, The Netherlands.

[22] Davidson, E.A., Swank, W.T. and Perry, T.O. (1986) Distinguishing between nitrification and denitrification as sources of gaseous nitrogen production in soil. Appl. Environ. Microbiol. $52,1280-1286$.

[23] Slater, J.M. and Capone, D.G. (1989) Nitrate requirement for acetylene inhibition of nitrous oxide reduction in marine sediments. Microb. Ecol. 17, 143-157.

[24] Rudolph, J., Frenzel, P. and Pfennig, N. (1991) Acetylene inhibition technique underestimates in situ denitrification rates in intact cores of freshwater sediment. FEMS Microbiol. Ecol. 85, 101-106.

[25] Simarmata, T., Benckiser, G. and Ottow, J.C.G. (1993) Effect of an increasing carbon-nitrate-n ratio on the reliability of acetylene in blocking the $\mathrm{N}_{2} \mathrm{O}$-reductase activity of denitrifying bacteria in soil. Biol. Fertil. Soils 15, 107-112.
[26] Culbertson, C.W., Zehnder, A.J.B. and Oremland, R.S. (1981) Anaerobic oxidation of acetylene by estuarine sediments and enrichment cultures. Appl. Environ. Microbiol. 41, 396-403.

[27] De Boer, W., Klein Gunnewiek, P.J.A., Kester, R.A., Tietema, A. and Laanbroek, H.J. (1993) The effect of acetylene on $\mathrm{N}$ transformations in an acid oak-beech soil. Plant and Soil 149, 292-296.

[28] Tiedje, J.M. (1982) Denitrification. In: Methods of Soil Analysis part 2: Chemical and Microbiological Properties (Page, A.L., Miller, R.H. and Keeney, D.R., Eds.), pp. 1011-1026, A.S.A and S.S.S.A, Madison, Wisconsin.

[29] Davidson, E.A., Matson, P.A., Vitousek, P.M., Riley, R., Dunkin, K., Garciamendez, G. and Maass, J.M. (1993) Processes regulating soil emissions of $\mathrm{NO}$ and $\mathrm{N}_{2} \mathrm{O}$ in a seasonally dry tropical forest. Ecology 74, 130-139.

[30] Miller, L.G., Coutlakis, M.D., Oremland, R.S. and Ward, B.B. (1993) Selective inhibition of ammonium oxidation and nitrification-linked $\mathrm{N} 2 \mathrm{O}$ formation by methyl fluoride and dimethyl ether. Appl. Environ. Microbiol. 59, 2457-2464.

[31] Fair, R.J., Jamieson, H.M. and Hopkins, D.W. (1994) Spatial distribution of nitrifying (ammonium-oxidizing) bacteria in soil. Lett. Appl. Microbiol. 18, 162-164.

[32] Revsbech, N.P. and Sørensen, J. (1990) Combined use of the acetylene inhibition technique and microsensors for quantification of denitrification in sediments and biofilms. In: Denitrification in Soil and Sediment (Revsbech, N.P. and Sørensen, J., Eds.), pp. 259-275. Plenum Press, New York. 